\title{
Managerial Ability, Players' Cultural Diversity, and Sporting and Economic Performance in English Soccer
}

\author{
Carlo Amenta ${ }^{1}$, Claudio Ballor ${ }^{2} \&$ Paolo Di Betta ${ }^{3}$ \\ ${ }^{1}$ DISMOT Department, University of Palermo, Italy \\ ${ }^{2}$ Infront Advanced Media Solutions, Milan, Italy \\ ${ }^{3}$ SEAF Department, University of Palermo, Italy \\ Correspondence: Paolo Di Betta, Università di Palermo, viale delle Scienze edificio 15, 90138 Palermo Italy. Tel: \\ 39-91-2389-5308. E-mail: paolo.dibetta@unipa.it
}

\author{
Received: August 27, 2012 Accepted: September 13, 2012 Online Published: November 7, 2012 \\ doi:10.5539/ijms.v4n6p116 URL: http://dx.doi.org/10.5539/ijms.v4n6p116
}

\begin{abstract}
We use a large homemade database on professional soccer in England to estimate the relevance of managerial ability on performance and the managerial skills in keeping up cultural diversity. The team manager faces a set of very complex tasks. Not only he is the head coach of the soccer team, thus influencing sporting performance, but he can also have an impact on performance, by improving economic efficiency or by limiting the organization innovation in order to foster the creation of organizational routines. The sporting competitive advantage translates into economic and financial performance; therefore the manager is a dominant voice in the financial viability of the club, too. We also measure the impact of cultural diversity: attendance appreciates home-grown and talented players, and dislikes cultural diversity.
\end{abstract}

Keywords: managerial capabilities, performance of soccer clubs, cultural diversity and xenophobia in sports

\section{Introduction}

Managerial ability is a source of value creation and organizational performance, and firms with superior managerial ability can realize superior performance advantage (Adner \& Helfat, 2003; Hansen et al. 2004). We focus on the managerial endowment in professional soccer clubs in the English Premier League and in the English Championship League. An empirical study devoted to a professional soccer as a single industry is interesting for two reasons: i) clubs are organizations primarily composed of experts; ii) innovation is sought season after season; iii) the context is rich of cultural diversity. The soccer industry is an interesting point in case because sports teams have comparable characteristics and societal goals, they share the common factor market and general environment (Holcomb et al. 2009: 459), therefore inter-industry comparisons can be made at a micro level (Peteraf \& Barney, 2003; Mahoney 1995). Resource productivity and performance can also be easily correlated to quality of the resources controlled within the club's boundaries. Our paper also belongs to the strategic management literature as far as contexts in strategy formation are concerned.

We concentrate on the role of the manager (we do not use capital letter), the head coach of a soccer club, who is responsible for the sporting performance and hence for all the aspects that concern the "production function" of the franchise. He is the head of the sporting team and supervises buying and selling players, hence a pivotal figure in resource bundling. He is also responsible for building and innovating capabilities in the team, for example by allowing home-grown players to rise to the first team, and in all the aspects that concern the well-being of the players, such as reducing their proneness to injuries and fastening their recover from forced rest period.

The sporting competitive advantage translates into economic and financial performance, therefore the manager is a dominant voice in the financial viability of the club, too. He is the protagonist in building the club's capabilities. He contributes to developing organizational capabilities, because he establishes organizational routines. He conducts the training, coordinates with the medical centre, establishes off-training days, decides whether players must retire in isolation to prepare for a match -a delicate decision, since it influences upon the sexual activity of the players and their private life. He is crucial in building up routines and therefore in developing organizational capabilities. Moreover, he supervises cross-functional integration among the administrative staff, medical staff, 
and the players. He is also responsible for higher-level capabilities to integrate lower-level capabilities (players) with other actors in the sporting arena, among which, we can list the media, the player's agent, competing clubs that offer to buy or sell players, the National teams and Federations which require players to participate to international country-based competitions such as the World Cup.

In the process of selecting resources, he is the crucial figure in deciding which player to buy or sell, he picks grass-roots players to play in the official team, and after hearing from the scouting department he decides to enlist promising athletes. Building a team is not only a matter of choosing the best players per position on the field, it is also a matter of choosing people that get along and play well together. The resources (the players) are barely imitable -because scarcely replicable- and transferable only if sold. Players can be loaned, and he must decide whether to do so, and a policy of alliances with other competing teams might help. Moreover, resources are durable to the extent that no injuries occur, and some players cannot play too much because more fragile. Therefore sporting competitive advantage is entirely based on the team (the mixture of players and the manager) and the medical staff.

We follow Lampel's (2001) definitions and scheme in tracking the core competencies of the firm, and we consider the club as a project-based firm aimed at winning the season or reaching an otherwise defined object -a certain level of performance, such as $4^{\text {th }}$ place- which is renewed each year. Lampel discusses upon the difficulties of fostering innovation in an environment such as that in which engineering-construction-procurement firms compete. He argues that the main difficulty is to balance efficiency and flexibility under conditions of diversity. We follow along these lines to sustain that the manager must show entrepreneurial, technical, evaluative, and relational competences to compete, innovate, and to conduct his own project-based endeavour - the club. In this context diversity must be considered as cultural diversity. He must build up the core competences in the club, by relying on tacit and codified knowledge, both in the profession and in the club. These concepts are well known and we abstain from dwelling on them, hence we just sketch the outline of a Manager's profile.

We think it is already clear how many qualities must a Manager bear and how similar these characteristics are to the Chairman of the Board and to the Chief Executive Officer of a Multinational company.

\subsection{Managing Experts}

The team is a collection expert: players are top experts in their field, highly paid and sought after. Players are an élite and must be treated accordingly, and leadership by the manager must be covert in the sense of Mintzberg (1998), who proposed the conductor of an orchestra as the archetypical covert leader. Even though it might sound paradoxical, leading a team of players is the same as leading a group of intellectuals (Quinn et al., 1996).

The manager must be capable of managing experts and expertise. The manager has to figure out the way the team should play, the position in executing the tactics on the field. He must be a charismatic leader capable of transmitting enthusiasm, endowed with the ability to discuss with the group and to command sufficient argumentative skills to convince people to adopt a tactical scheme or even to accept a marginal role whenever deemed instrumental to the success of the team -sometimes even to accept not playing a game. The manager has to choose players not only according to their talent, but also on the ability to mix with each other and to adapt to a common denominator of standard behaviour, on-field and off-field. In dealing with experts the manager is not alone, he needs the support of a well-established group of executives in the club. A tenured manager in a club develops routines with those executives that should induce better performance. We predict:

\section{H1: Bigger and more financial solid clubs show more stable and more tenured managers.}

\subsection{Managing Innovation}

Each season is as if a new project for the club. The objectives are adjourned, often with the injection of new players to substitute others. The manager himself might be new to the club, too. The financial situation of the club or the property might have been changed. A disappointing past season might linger on and the relationship with the fans might be strained, or else big results might have risen expectations for the incoming season, therefore the manager has to find an equilibrium between what might be reasonably gained and the fans', the players', the shareholders' expectations. Players turnover, debutant home-grown players in the first team are innovations in production. Home-grown players are often well known, often locals, and usually supporters' favourites. We predict:

H2: Innovation in players from considerable player changes might cause stress in the camaraderie among players, blocking the formation of organizational routines, therefore worsening performance.

H3: The rise of home-grown players to the team will be well-accepted by the public at the stadium but could 


\section{affect performance.}

\subsection{Managing Cultural Diversity}

Each club has a certain degree of cultural diversity. In a soccer club players come from all over the world, bringing along not only diverse cultures as far as their background and education is concerned, but also the very idea of the way soccer should be played. Therefore the manager has to collect these forces together and find a thread that unites the team. Managerial skills in keeping up with cultural diversity are very relevant in professional sports, where talent is not related to nationality.

Dealing with diverse cultures is very difficult, and even more so when chauvinism and national profiling is present in the game (not to say about racial issues, too), sometimes even by some supporters of the team or from opposing clubs. Hence, the manager must also be capable in isolating those supporters and ban them from the agreed-upon, commonly accepted rules in the community that build up the team. He must also calm down his own players not to react to provocation from opposing team's hooligans that inveigh against and curse. Not to forget that he must also be able to keep calm in front of such criminal behaviour.

H4: Cultural diversity has a positive effect on performance, whereas a chauvinism attendance might contrast non-native players.

\section{Method}

In order to test research hypothesis we consider two empirical models. In the first model we focus on team performance. We use the entire database (Premier League and Championship), composed of 53 teams for 5 years, from 2001/02 to 2005/06, a total of 265 observations. The first model is:

$$
\begin{array}{r}
\text { points }_{i}=\beta_{0}+\beta_{1} \text { dmanch }_{i}+\beta_{2} \text { homegrownpercentage }_{i}+\beta_{3} \text { attendance }_{i}+\beta_{4} \text { intensityoftradingout }_{i}+ \\
\beta_{5} \text { dumpremier }_{i}+\varepsilon_{i}
\end{array}
$$

The dependent is a count variable (a non-negative integer) so we modelled it as Poisson-distributed. In order to account for simultaneity between points gained (points) and change of the manager (dmanch) we estimated it by two stage least squares.

The second model addresses cultural diversity by considering the Premier League only, 28 teams for 5 years (140 observation). We estimate a system of three equations ((2)-(3)-(4)) by seemingly unrelated regression (SUR), after Zellner (1962):

$$
\begin{aligned}
& \text { points }_{i}=\beta_{0}+\beta_{1} \text { dmanch }_{i}+\beta_{2} \text { wagesandsalariescost }_{i}+\beta_{3} \text { homegrownpercentage }_{i}+\beta_{4} \text { attendance }_{i}+\beta_{5} \\
& \text { intensityoftradingouti }+\beta 6 \text { foreignpli }+\varepsilon i \\
& \text { dmanch }_{i}=\beta_{0}+\beta_{1} \text { points }_{i}+\beta_{2} \text { margin }_{i}+\beta_{3} \text { intensityoftradingout }_{i}+\beta_{4} \text { nettransferexpenditur }_{i}+\beta_{5} \text { netfundsdebt }_{i} \\
& +\beta_{6} \text { foreignpl }_{i}+\beta_{7} \text { homegrownpercentage }_{i}+\beta_{8} \text { pretaxprofitloss }_{i}+\beta_{9} \text { netassetsliabilities }_{i}+\varepsilon_{i} \\
& \text { attendance }_{i}=\beta_{0}+\beta_{1} \text { foreignpl }_{i}+\beta_{2} \text { dmanch }_{i}+\beta_{3} \text { points }_{i}+\beta_{4} \text { wagesandsalariescost }_{i}+\beta_{5} \\
& \text { homegrownpercentage }{ }_{i}+\beta_{6} \text { intensityoftradingout }_{i}+\varepsilon_{i}
\end{aligned}
$$

For both models we apply a pooled estimator without considering individual or time-constant effect. The database is built up through different sources, both online and as printed documents. The main ones were the website of football statistics (www.soccerbase.com), and the Deloitte Annual Review of Football Finance. Regarding the latter, we worked on the 2003 to 2007 editions.

The firm performance is measured by the variable points. It consists of the total number of points collected by the team in each season. dmanch is a dummy variable accounting for managerial change. It takes the value 1 if the manager has been changed in the season, 0 otherwise. Change in the manager should have a negative effect on points, but the change might be the result of a negative stream of results, therefore we treat the two variables as endogenous (a simultaneity problem with the dependent variable). This forces us to use the two stages estimation in the first model. homegrownpercentage measures the deployment of home-grown players by dividing the number of matches in which they appear in the starting roster, on the total possible caps per season (obtained by multiplying the total number of matches per season for the number of players that start the match). A home-grown in the starting roster is a strong signal that the team managerial board is committed to fully exploiting internally developed resources. attendance is the people who attended home matches during the season. intensityoftradinginout is the algebraic sum of players acquired and sold during the transfer market period, a proxy for organization innovation. dumpremier is a dummy variable accounting for the competitive environment characteristics. It takes the value 1 if the team plays in the Premier League and 0 if it plays in the 
Championship. We consider the Premier a more competitive environment.

Other variables used in the SUR model are wageandsalariescost, the pay in the fiscal year for wages to players in the roster, a proxy for talent, foreignpl, a variable built up by summing up the total number of foreign players that played in a specific season (http://en.wikipedia.org/wiki/List_of_foreign_Premier_League_players). It is a proxy for cultural diversity and it is calculated only for premier league teams. Note that there are also financial and economic variables: margin is the difference between turnover and wages. nettransferexpenditure consider the net financial result of players trading during the transfer period and measures managerial efficiency. Other, self-explanatory managerial variables are netfundsdebt, netassetsliabilities and pretaxprofitloss.

\section{Results}

The first model (two stage estimation) is reported in Tab. 1; standard errors are corrected for heteroscedasticity. This is a two stage regression as suggested by Cameron and Trivedi (2009, section 17.5.1), wherein in the first stage we regressed dmanch on the list of the other variables and the change in manager the preceding season (that acts as an instrumental variable). In the second stage the residuals from the first stage (dmanchhat) are included as a regressor.

Table 1. Performance in the Premier and Championship Leagues as determined by the manager, the dependent variable is points

\begin{tabular}{ll}
\hline Regressors & Coefficients \\
\hline dmanch & 1.094202 \\
& $(1.153556)$ \\
margin & $0.0115824 *$ \\
& $(0.0057886)$ \\
homegrownpercentage & $-1.043454 *$ \\
& $(0.4684013)$ \\
attendance & -0.0003882 \\
& $(0.0085333)$ \\
intensityoftradingout & -0.041864 \\
& $(0.033603)$ \\
dumpremier & $-0.6451248 * * *$ \\
& $(0.0810036)$ \\
dmanchhat & $-1.218941 * * *$ \\
& $(1.150176)$ \\
constant & $4.624632 * * *$ \\
& $(0.3489234)$ \\
& Observations: 158 \\
& Wald $\chi^{2}(7)=174.52$, \\
& p-value $=0.0000$ \\
& Pseudo $\mathrm{R}^{2}=0.2164$ \\
\hline
\end{tabular}

Two stage regression, dmanchhat are residuals from the first stage. ${ }^{* * *}=$ significant at $1 \%, * *=$ significant at $5 \%$, $*=$ significant at $10 \%$

The statistically significant variables are: margin (at 5\% level), homegrownpercentage (5\%) and dumpremier (.1\%) All the coefficients can be interpreted as a semi elasticity. An increase of one pound sterling in the difference between turnover and wages (margin) is associated with a $1,1 \%$ increase in points gained. It can be considered a measure of the impact of managerial efficiency on performance. The other two significant variables have a negative impact on teams performance. The exploitation of internal resources like home-grown players, that partially accounts managerial innovation, does not result in a positive impact on performance as hypothesized in the second part of $H 3$. Premier league can be considered a more competitive environment: to a team playing in the premier (dumpremier $=1$ ) is associated a $64 \%$ decrease in points gained.

Our results reject hypothesis $H 2$, as far as organization innovation is concerned, as measured by the total numbers of players changed (intensityoftradinginout) is not significant for team performance. Management tenure (dmanch) and market size (attendance) are non significant, so manager can have an impact on performance only by improving economic efficiency (margin) or limiting the organization innovation in order to 
foster the creation of organizational routines.

The SUR model is used to analyze cultural diversity, economic determinants of manager tenure, and home-grown players appeal for team demand (hypotheses $H 1, H 3$, and H4), see Tab. 2. The database contains only premier league teams because we are interested in cultural diversity effect measured by the variable foreignpl. Errors are corrected for heteroscedasticity.

Table 2. Cultural diversity and the manager in the Premier League

\begin{tabular}{|c|c|c|c|}
\hline $\begin{array}{l}\text { Equation } \\
\text { for: }\end{array}$ & regressors & $\begin{array}{l}\text { Bootstrap } \\
\text { Coefficient }\end{array}$ & $\begin{array}{l}\text { Standard } \\
\text { Errors } \\
\end{array}$ \\
\hline \multicolumn{4}{|l|}{ points } \\
\hline & dmanch & $-9.11738 * *$ & 3.588623 \\
\hline & wagesalariescosts & $0.476111^{* * *}$ & 0.149883 \\
\hline & homegrownpercentage & 3.265402 & 13.83664 \\
\hline & attendance & 0.152754 & 0.276037 \\
\hline & intensityoftradingout & $-0.38611^{*}$ & 0.220228 \\
\hline & foreignpl & 0.599919 & 0.380288 \\
\hline & constant & $27.32348^{* * *}$ & 7.665537 \\
\hline & $\mathrm{R}^{2}=0.7199$ & $\chi^{2}=253.90$ & \\
\hline & RMSE $=8.535647$ & $(0.0000)$ & \\
\hline \multicolumn{4}{|l|}{ dmanch } \\
\hline & points & -0.00782 & 0.005936 \\
\hline & margin & 0.005506 & 0.004267 \\
\hline & intensityoftradingout & $0.032519 * * *$ & 0.010429 \\
\hline & nettransferexpenditure & -0.00014 & 0.000345 \\
\hline & netfundsdebt & -0.00043 & 0.000278 \\
\hline & foreignpl & 0.006791 & 0.012314 \\
\hline & homegrownpercentage & $1.077705^{*}$ & 0.551392 \\
\hline & pretaxprofitloss & $-5.9 \mathrm{E}-05$ & 0.000137 \\
\hline & netassetsliabilities & -0.00102 & 0.000773 \\
\hline & constant & -0.07947 & 0.28815 \\
\hline & $\mathrm{R}^{2}=0.2575$ & $\chi^{2}=37.18$ & \\
\hline & $\mathrm{RMSE}=.351288$ & $(0.0000)$ & \\
\hline \multicolumn{4}{|l|}{ attendance } \\
\hline & foreignpl & $-0.95575 * * *$ & 0.279356 \\
\hline & dmanch & 0.750895 & 3.263077 \\
\hline & points & 0.09342 & 0.167227 \\
\hline & wagesalariescosts & $0.322518^{* * *}$ & 0.114054 \\
\hline & homegrownpercentage & $34.34929 * * *$ & 10.29249 \\
\hline & intensityoftradingout & -0.06985 & 0.192669 \\
\hline & constant & $23.82331 * * *$ & 5.383164 \\
\hline & $\mathrm{R}^{2}=0.6562$ & $\chi^{2}=183.37$ & \\
\hline & $\mathrm{RMSE}=6.672897$ & $(0.0000)$ & \\
\hline
\end{tabular}

Seemingly unrelated regression (SUR), 95 observations, bootstrap standard errors. $* * *=$ significant at $1 \%$, $* *=$ significant at $5 \%, *=$ significant at $10 \%$

In the first equation concerns sporting performance. We observe a negative effect of manager change (dmanch) and organization innovation (intensityoftradinginout), so that hypothesis $\mathrm{H} 2$ is not rejected. Increasing talent by acquiring more expensive players results in a radical improvement in performance. The second equation concerns manager tenure. The dependent variable is a dummy, hence it can be given a probabilistic interpretation. We observe that organization innovation from changing players (intensityoftradinginout) and home-grown players deployment is associated with an increase in the probability of a change. As the economic and financial variables are not significant we conclude that hypothesis $H 1$ is rejected. The third equation measures a performance in marketing. Demand appreciates both home-grown and talented players, while cultural diversity (foreignpl) has a negative impact (as hypothesized). 
The SUR estimation allows us to test the possibility of running single equation ordinary least squares (OLS), instead of the system of equations. Note that the correlation of residuals is 0.1173 for dmanch and points, -0.0027 between attendance and dmanch, -0.0597 between attendance and points. The Breusch-Pagan test of independence gives $\chi^{2}(3)=1.647$, it does not reject the null hypothesis of independence between the equations (p-value: 0.6487 ). The three equations can be estimated by OLS.

\section{Discussion}

Our case-study follows Holcomb et al. (2009) in using sports as a setting to measure managerial ability as a source of performance and value creation. As they point out $(2009,480)$, professional sports have certain peculiarities that suggest caution in speculating about generalizing these findings. However, we find particularly attractive the possibility of directly testing the acceptance of cultural diversity within the team and the possibility of directly comparing the performance to acceptance in the attendance at the stadium. Comparisons of such a scale are not possible in other industrial settings. Our results suggest that, contrary to our expectation, financial and economic situation do not affect manager tenure while organization innovation has a negative impact on performance in a context where organizational routines could play a determinant role. Internal resources exploitation has a positive impact from marketing perspective but can reduce team performance because of loss of cohesion and experience in the team. Cultural diversity has a negative impact from a marketing perspective. We considered attendance at stadium only, which is around one third of team revenues. Evidently, prejudices go against self-interest but it is reasonable to hypothesizes that the inclusion of TV rights revenues as a proxy for world-wide demand should change the picture.

\section{Acknowledgements}

A preliminary version was presented at the SMS Annual Conference "Strategic Management at the Crossroads" held in Rome, September 12-15, 2010. Amenta is responsible for section 3, Ballor for section 4, Di Betta for section 1. Section 2 was written together. The database was set up by Ballor in 2007 for his thesis for the Master of Advanced Studies in Sport Administration and Technology, University of Lausanne (Switzerland).

\section{References}

Adner, R., \& Helfat, C. E. (2003). Corporate Effects and Dynamic Managerial Capabilities. Strategic Management Journal, 24(10) October Special Issue, 1011-1025. http://dx.doi.org/10.1002/smj.331

Cameron, A. C., \& Trivedi, P. K. (2009). Microeconometrics Using Stata. College Station TX USA: Stata Press.

Deloitte. (2001, 2002, 2003, 2004, 2005, 2006, 2007). Annual Review of Football Finance.

Hansen, M. H., Perry, L. T., \& Reese, C. S. (2004). A Bayesian Operazionalization of the Resource-Based View. Strategic Management Journal, 25(13), 1279-1295. http://dx.doi.org/10.1002/smj.432

Holcomb, T. R., Holmes, R. M. Jr., \& Connelly, B. L. (2009). Making the Most of What You Have: Managerial Ability As a Source of Resource Value Creation. Strategic Management Journal, 30(5), 457-485. http://dx.doi.org/10.1002/smj.747

http://en.wikipedia.org/wiki/List_of_foreign_Premier_League_players

Lampel, J. (2001). The Core Competencies of Effective Project Execution: The Challenge of Diversity. International Journal of Project Management, 19(8), 471-483.

Mahoney, J. T. (1995). The Management of Resources and the Resources of Management. Journal of Business Research, 33(29), 91-101. http://dx.doi.org/10.1016/0148-2963(94)00060-R

Mintzberg, H. (1998). Covert Leadership: Notes on Managing Professionals. Harvard Business Review, Nov.-Dec., 140-147.

Peteraf, M. A., \& Barney, J. B. (2003). Unraveling the Resource-Based Tangle. Managerial and Decision Economics, 24(4), 309-323. http://dx.doi.org/10.1002/mde.1126

Quinn, J. B., Anderson, P., \& Finkelstein, S. (1996). Managing Expertise. Academy of Management Executive, 10(3), 7-27.

www.soccerbase.com

Zellner, A. (1962). An efficient method of estimating seemingly unrelated regressions and tests for aggregation bias. Journal of the American Statistical Association, 57, 348-368. 